\title{
Effects of lactobacillus plantarum ZJ316 on pig growth and pork quality
}

\author{
Cheng Suo ${ }^{1+}$, Yeshi Yin² ${ }^{2 *}$, Xiaona Wang ${ }^{1}$, Xiuyu Lou' ${ }^{1}$ Dafeng Song ${ }^{1}$, Xin Wang ${ }^{2}$ and Qing Gu ${ }^{1 *}$
}

\begin{abstract}
Background: Lactobacillus plantarum is a plant-associated bacterial species but it has also been found in human, mouse and porcine gastrointestinal tracts. It can ferment a broad spectrum of plant carbohydrates; it is tolerant of bile salts and low pH, and it has antagonistic potential against intestinal pathogens. However, experiments reporting the use of $L$. plantarum as a probiotic are limited. In this study, the effects of L. plantarum ZJ316 isolated from infant fecal samples on pig growth and pork quality were investigated.

Results: One hundred and fifty newly weaned pigs were selected randomly and divided into five groups. Group 1 was fed a diet supplemented with the antibiotic mequindox; Groups 2, 3 and 4 were fed a diet supplemented with L. plantarum and no antibiotic; and Group 5 was fed a mixture of mequindox and L. plantarum. After a 60 days initial treatment, samples were collected for evaluation. The results showed that, the L. plantarum ZJ316 has probiotic effects on pig growth and that these effects are dose dependent. The effects of a dose of $1 \times 10^{9} \mathrm{CFU} / \mathrm{d}$ were more pronounced than those of a dose of $5 \times 10^{9} \mathrm{CFU} / \mathrm{d}$ or $1 \times 10^{10} \mathrm{CFU} / \mathrm{d}$. In Group $2\left(1 \times 10^{9} \mathrm{CFU} / \mathrm{d}\right)$, the diarrhea $(p=0.000)$ and mortality rates $(p=0.448)$ were lower than in antibiotic-treated pigs (Group 1$)$, and the daily weight gain $(p=0.001)$ and food conversion ratios were better $(p=0.005)$. Improved pork quality was associated with Lactobacillus treatment. $\mathrm{pH}(45 \mathrm{~min}, \mathrm{p}=0.020)$, hardness $(p=0.000)$, stickiness $(p=0.044)$, chewiness $(p=0.000)$, gumminess $(p=0.000)$ and restoring force $(p=0.004)$ were all significantly improved in Lactobacillus-treated pigs (Group 2). Although we found that L. plantarum exerted probiotic effects on pig growth and pork quality, the mechanisms underlying its action require further study. Polymerase chain reaction-denaturing gradient gel electrophoresis results showed that the gut bacterial communities in Lactobacillus- and antibiotic-treated pigs were very similar and the quantity of L. plantarum ZJ316 was below the detection limits of DGGE-band sequencing. The concentration of short-chain fatty acids in Lactobacillus- and antibiotic-treated fecal samples were not significantly different $(p=0.086)$. However, the villus height of ilea $(p=0.003)$, jejuna $(p=0.000)$ and duodena $(p=0.036)$ were found to be significantly improved by Lactobacillus treatment.
\end{abstract}

Conclusion: L. plantarum ZJ316 was found to have probiotic effects, improving pig growth and pork quality. The probiotic mechanism might not involve L. plantarum colonization and alteration of the gut bacterial community. Rather, it might be related to the inhibition of the growth of opportunistic pathogens and promotion of increased villus height.

Keywords: Probiotics, Lactobacillus plantarum, Pig, Pork quality

\footnotetext{
*Correspondence: yinyeshi@126.com; guqing2002@hotmail.com

${ }^{\dagger}$ Equal contributors

${ }^{1}$ Department of Biotechnology, College of Food Science and Biotechnology,

Zhejiang Gongshang University, No. 149, Jiaogong Road, Hangzhou 310035,

China

${ }^{2}$ Institute of Plant Protection and Microbiology, Zhejiang Academy of

Agricultural Sciences, No. 198, Shiqiao Road, Hangzhou 310021, China
} 


\section{Background}

Weaning stress can destroy the balance of intestinal microbiota in young mammals. Such periods of stress may allow opportunistic pathogens to multiply and cause gastrointestinal (GI) disorders [1]. To promote growth and reduce the incidence of diarrhea, subtherapeutic antibiotics have been widely used in pig diets [2]. However, this procedure has public health consequences because of the high risk of the development of antimicrobial resistance among pathogenic bacteria, which may be then transferred to humans [3,4]. It is therefore necessary to find ways to replace antibiotics in pig feeding strategies.

Several members of Lactobacillus, which is part of the normal mucosal microbiota of pigs, have been found to be good probiotics [5,6]. Lactobacillus and similar bacteria, as well as their metabolites, can control pathogens, such as Escherichia coli [7,8], Salmonella typhimurium [9], and others. Selected strains of L. plantarum possess properties that make them promising candidates for probiotics in feed additives [10]. However, experiments reporting the use of L. plantarum as a probiotic are limited. Pieper et al. determined whether a single administration of L. plantarum DSMZ 8862/8866 either before or at the time of weaning can affect the intestinal microbiota of pigs. The results showed that L. plantarum DSMZ 8862/8866 has positive results on GI health [11]. The effects were found to be better when the probiotics were administered at the time of weaning than when they were administered before weaning.

Due to the high mortality of pigs after removing antibiotics at weaning (unpublished data), most farmers are reluctant to accept this option [12]. In this study, we determined whether L. plantarum could replace commonly used antibiotics. We also investigated the effects of L. plantarum ZJ316 on pig growth, pork quality, gut morphology and gut microbiota.

\section{Results}

\section{Inhibitory effects of L. Plantarum ZJ316 culture} supernatants

As shown in Table 1, the culture supernatants of $L$. plantarum ZJ316 had strong inhibitory effects on some pathogenic bacteria, such as Salmonella, Escherichia coli, and Listeria monocytogenes. However, probiotics such as L. fermentum, Lactococcus lactis and Saccharomyces cerevisiae were not inhibited by the culture supernatants of L. plantarum ZJ316. These results showed that the strain L. plantarum ZJ316 may be a good probiotic. As shown in Additional file 1 Figure S1, the supernatants still exhibited an inhibitory effect on Escherichia coli and Salmonella after the $\mathrm{pH}$ was adjusted to 6.0. This observation indicates that the inhibitory effect was not only due to the low $\mathrm{pH}$. We also investigated the effects of
Table 1 Inhibition spectrum of culture supernatants of $L$. plantarum ZJ316

\begin{tabular}{lc}
\hline Bacterial name & Inhibitory effects \\
\hline Acetic bacteria & - \\
\hline Bacillus subtilis & + \\
\hline E. coli & +++ \\
\hline Lactobacillus fermenti & - \\
\hline Lactobacillus plantarum ZJ316 & - \\
\hline Lactococcus lactis & - \\
\hline Listeria monocytogenes & ++ \\
\hline Micrococcus luteus & + \\
\hline Pseudomonas aeruginosa & + \\
\hline Pseudomonas putida & ++++ \\
\hline Shigella flexneri & ++ \\
\hline Saccharomyces cerevisiae & - \\
\hline Salmonella & ++ \\
\hline Shigella dysenteriae & + \\
\hline Staphylococcus aureus & + \\
\hline Staphylococcus citreus & + \\
\hline Vibrio parahaemolyticus & + \\
\hline Inhibition zone in diameter $(\mathrm{mm}):+++, 19-24 \cdot++, 15-18 \cdot+, 10-15 \cdot-, n o$
\end{tabular}

*, Inhibition zone in diameter (mm): +++, 19-24; ++, 15-18; +, 10-15; -, no observed inhibit effect.

two main short-chain fatty acids on bacterial inhibition. The results showed that at $\mathrm{pH} 3.5$, acetic acid and lactic acid cannot inhibit the growth of indicator bacteria (Additional file 1 Figure S2).

\section{Effects of $L$. Plantarum ZJ316 on pig growth}

As shown in Table 2, different treatments affected pig growth. Compared to group 1 (which was treated with mequindox), other groups treated with Lactobacillus or treated with both showed better pig growth. The average daily gain and food conversion ratio was higher improved in the Lactobacillus-treated groups than in Group 1. Group 2 showed significantly better growth performance than Group 1. Diarrhea ratios were significantly lower in Lactobacillus-treated groups than in Group 1. The effect of Lactobacillus on pig growth varied according to dosage. The effects in Group 2 $\left(1 \times 10^{9} \mathrm{CFU} /\right.$ day $)$ were more pronounced than in Group $3\left(5 \times 10^{9} \mathrm{CFU} /\right.$ day $)$ or Group $4\left(1 \times 10^{10} \mathrm{CFU} /\right.$ day $)$. In general, mequindox was found to improve the probiotic effects of high dosages of Lactobacillus. In Groups 4 and 5 , pigs were given the same dose of Lactobacillus $\left(1 \times 10^{10} \mathrm{CFU} /\right.$ day $)$ orally. Mequindox was added to the diet fed to pigs in Group 5. The results showed that mequindox affected the probiotic effects on pig growth, but these effects were not significant.

The effects of $L$. plantarum ZJ316 on growth was more pronounced in Group 2 than in Groups 3, 4, or 5. 
Table 2 Effects of different treatments on pig growth parameters, mortality and prevalence of diarrhea\#

\begin{tabular}{llllll}
\hline & Group 1 & Group 2 & Group 3 & Group 4 & Group 5 \\
\hline Food intake (g/day) & $974.21 \pm 5.51^{\mathrm{a}}$ & $911.42 \pm 34.50^{\mathrm{ab}}$ & $864.81 \pm 43.78^{\mathrm{b}}$ & $901.39 \pm 44.51^{\mathrm{ab}}$ & $860.80 \pm 19.73^{\mathrm{b}}$ \\
\hline Daily gain (g/day) & $454.90 \pm 18.14^{\mathrm{a}}$ & $520.30 \pm 9.29^{\mathrm{b}}$ & $470.20 \pm 13.27^{\mathrm{a}}$ & $477.50 \pm 13.87^{\mathrm{a}}$ & $469.30 \pm 10.31^{\mathrm{a}}$ \\
\hline Food conversion ratio & $2.23 \pm 0.08^{\mathrm{a}}$ & $1.76 \pm 0.12^{\mathrm{b}}$ & $1.85 \pm 0.15^{\mathrm{b}}$ & $1.89 \pm 0.04^{\mathrm{b}}$ & $1.83 \pm 0.02^{\mathrm{b}}$ \\
\hline Mortality (\%) & $10.00 \pm 10.00^{\mathrm{a}}$ & $3.33 \pm 3.33^{\mathrm{a}}$ & $3.33 \pm 3.33^{\mathrm{a}}$ & $6.67 \pm 6.67^{\mathrm{a}}$ & $3.33 \pm 3.33^{\mathrm{a}}$ \\
\hline Diarrhea (\%) & $7.06 \pm 0.66^{\mathrm{a}}$ & $2.17 \pm 0.10^{\mathrm{b}}$ & $2.28 \pm 0.20^{\mathrm{b}}$ & $3.39 \pm 0.78^{\mathrm{bc}}$ & $4.28 \pm 0.22^{\mathrm{c}}$ \\
\hline
\end{tabular}

\#Group 1 represents pigs treated with antibiotics $105 \mathrm{mg} /$ day. Groups 2, 3, and 4 represent pigs treated with L. plantarum ZJ316 $1 \times 10^{9} \mathrm{CFU} / \mathrm{d}, 5 \times 10^{9} \mathrm{CFU} / \mathrm{d}$, and $1 \times 10^{10} \mathrm{CFU} / \mathrm{d}$, respectively. Group 5 represents pigs treated with antibiotics $105 \mathrm{mg} / \mathrm{d}$ and L. plantarum ZJ316 $1 \times 10^{10} \mathrm{CFU} / \mathrm{d}$. All values are expressed as mean \pm standard error.

$a, b$ and $c$ Different superscript letters within a row represent statistically significant differences among groups $(p<0.05)$.

Only pigs in groups 1 and 2 were selected for further analysis.

\section{Effects of L. Plantarum ZJ316 on pork quality}

Three pigs selected randomly from Group 1, and six pigs selected randomly from Group 2 were killed for evaluation of pork quality. In Group 2, three pigs were killed after cessation of addition of Lactobacillus to their diet. These pigs are here referred to as Group 2-1. The remaining three pigs in Group 2 were killed one week after cessation of the addition of Lactobacillus, and are here referred to as Group 2-2. As shown in Table 3, the pork quality was different between antibiotic- and Lactobacillus-treated pigs. The $\mathrm{pH}$ (45 min) and several meat texture evaluation parameters, such as hardness, stickiness, chewiness, gumminess and restoring force were significantly improved by Lactobacillus (Group 2-1) compared with antibiotic-treated pigs. More interesting is the fact that the pork quality had some changes one week after stopping Lactobacillus treatment. The lightness, $\nabla \mathrm{E}$, drop loss $(24 \mathrm{~h})$, hardness, stickiness, chewiness, gumminess and restoring force of longissimus were significantly changed one week after cessation of the inclusion of Lactobacillus.

\section{Histologic alterations of intestinal ileal mucosa}

No features suggesting histopathology in the ilea, jejuna and duodena of antibiotic- and Lactobacillus-treated

Table 3 Parameters used for evaluation of pork quality ${ }^{\#}$

\begin{tabular}{|c|c|c|c|c|}
\hline & & Group 1 & Group 2-1 & Group 2-2 \\
\hline \multirow[t]{4}{*}{ Longissimus muscle color } & Lightness & $39.06 \pm 1.13^{\mathrm{ab}}$ & $41.58 \pm 1.71^{\mathrm{a}}$ & $35.39 \pm 0.96^{b}$ \\
\hline & Redness & $5.10 \pm 0.92^{a}$ & $5.95 \pm 0.11^{a}$ & $4.48 \pm 0.70^{a}$ \\
\hline & Yellowness & $1.88 \pm 0.29^{a}$ & $2.42 \pm 0.30^{\mathrm{a}}$ & $1.57 \pm 0.41^{\mathrm{a}}$ \\
\hline & $\overline{\nabla E}$ & $55.72 \pm 1.04^{\mathrm{ab}}$ & $52.47 \pm 2.51^{a}$ & $59.97 \pm 0.93^{b}$ \\
\hline \multirow[t]{4}{*}{ Fillet color } & Lightness & $49.60 \pm 5.03^{\mathrm{a}}$ & $45.82 \pm 3.39^{\mathrm{ab}}$ & $39.08 \pm 0.40^{b}$ \\
\hline & Redness & $10.93 \pm 0.92^{a}$ & $11.16 \pm 0.85^{a}$ & $9.11 \pm 0.61^{a}$ \\
\hline & Yellowness & $3.73 \pm 0.99^{a}$ & $3.18 \pm 0.57^{a}$ & $2.07 \pm 0.06^{a}$ \\
\hline & $\overline{\nabla E}$ & $47.04 \pm 4.64^{a}$ & $50.66 \pm 3.14^{\mathrm{ab}}$ & $56.86 \pm 0.36^{b}$ \\
\hline \multirow[t]{2}{*}{$\overline{\mathrm{pH} \text { value }}$} & 45 minutes & $6.25 \pm 0.01^{a}$ & $6.38 \pm 0.03^{b}$ & $6.39 \pm 0.04^{b}$ \\
\hline & 24 hours & $5.82 \pm 0.04^{\mathrm{a}}$ & $5.84 \pm 0.02^{\mathrm{a}}$ & $5.83 \pm 0.03^{\mathrm{a}}$ \\
\hline \multirow[t]{2}{*}{ Drip loss (\%) } & 24 hours & $5.95 \pm 0.94^{a}$ & $5.70 \pm 1.01^{a}$ & $2.84 \pm 0.30^{b}$ \\
\hline & 48 hours & $3.28 \pm 0.42^{a}$ & $2.80 \pm 0.69^{\mathrm{ab}}$ & $1.70 \pm 0.29^{b}$ \\
\hline Marbling score & & $3.02 \pm 0.12^{a}$ & $3.25 \pm 0.12^{\mathrm{a}}$ & $3.25 \pm 0.12^{\mathrm{a}}$ \\
\hline Hardness (g) & & $209.43 \pm 16.50^{a}$ & $138.47 \pm 6.70^{b}$ & $75.03 \pm 7.27^{c}$ \\
\hline Stickiness (g.s) & & $-4.43 \pm 0.39^{a}$ & $-6.88 \pm 1.30^{b}$ & $-2.82 \pm 0.38^{\mathrm{a}}$ \\
\hline Springiness & & $1.01 \pm 0.02^{a}$ & $0.96 \pm 0.03^{a}$ & $1.09 \pm 0.08^{\mathrm{a}}$ \\
\hline Chewiness & & $152.14 \pm 13.50^{a}$ & $93.51 \pm 8.57^{b}$ & $61.35 \pm 5.45^{c}$ \\
\hline Gumminess & & $153.96 \pm 10.27^{a}$ & $97.80 \pm 10.35^{b}$ & $55.59 \pm 7.61^{c}$ \\
\hline Cohesiveness & & $0.73 \pm 0.01^{a}$ & $0.71 \pm 0.02^{a}$ & $0.73 \pm 0.01^{\mathrm{a}}$ \\
\hline Restoring force & & $0.46 \pm 0.03^{a}$ & $0.35 \pm 0.02^{b}$ & $0.42 \pm 0.02^{a}$ \\
\hline
\end{tabular}

"Group 1 represents samples collected from pigs treated with antibiotics $105 \mathrm{mg} / \mathrm{d}$. Group 2 represents samples collected from pigs treated with $L$. plantarum ZJ316 $1 \times 10^{9} \mathrm{CFU} / \mathrm{d}$. Group 2-1 represents samples collected immediately after the cessation of $L$. plantarum and Group 2-2 represents samples collected one week after the cessation of $L$. plantarum. All values represent mean \pm standard error.

$a, b$ and $c$ Different superscript letters within a row represent statistically significant differences among groups $(p<0.05)$. 
pigs were observed at any time during this study. The intestinal mucosa was regularly organized in intestinal villi and crypts in both groups. The height and thickness of the villi differed across treatment groups. In the Lactobacillus-treated group, the height of the villi was greater and the density was thicker than in the antibiotic-treated group. After microscopic observation, villus height and crypt depth were quantified using a Leica MZ16A (Leica, Germany). The ratio of villus height to crypt depth was calculated and the results are listed in Table 4. The results showed that the villus height in the ilea, jejuna and duodena of Lactobacillustreated pigs (Group 2-1) was significantly greater than that of antibiotic-treated pigs (Group 1). In group 2-2, the villus height in the duodena and the crypt depth in the jejuna were significantly greater one week after cessation of Lactobacillus exposure.

\section{Changes in the gut bacterial community due to different treatments}

DGGE profiles of PCR products of the $16 \mathrm{~S}$ rRNA gene V3 region from pig fecal, ileal mucosa and cecal contents revealed that the overall bacterial community was not significantly changed by Lactobacillus treatment (Group 2-1 and 2-2) compared to antibiotic-treated (Group 1). Before starting this experiment, the bacterial community of pig fecal samples were randomly distributed and varied due to individual animal differences (Figure 1A). The patterns of DGGE bands in fecal, cecal and ileal samples were similar between antibiotic- and Lactobacillus-treated groups (Figures 1B, 1C and 1D). To obtain an objective interpretation of the electrophoretic patterns of the different treatment groups, the samples were subjected to a numerical analysis based on the Dice similarity coefficient, then used for cluster analysis. As shown in Figure 1, the cluster analysis results indicated that the bacterial community in fecal, cecal and ileal samples did not show major changes between antibiotic and Lactobacillus treatment. Samples taken from different treatment groups were distributed randomly in the cluster tree.

To determine whether the L. plantarum ZJ316 colonized in pigs' guts, most of the single DGGE bands were excised for cloning and sequencing. Three clones were selected randomly from each band for sequencing. The sequences were then identified using a Blast search. The bacteria with highest value for each band are listed in Table 5. No bands showing significant similarity to Lactobacillus appeared before the start of treatment. At the end of this study, we observed two bands from fecal samples, two bands from cecal contents and 1 band from ileum mucosa that showed pronounced similarity to Lactobacillus. No band showed pronounced similarity to L. plantarum.

\section{Changes in the concentration of short-chained fatty acids (SCFAs) in pig fecal samples}

Although the concentration of most SCFAs was greater in the Lactobacillus-treated group (Group 2), the difference between antibiotic- and Lactobacillus-treated groups was not significant (Table 6).

\section{The inhibitory effects of mequindox on L. Plantarum ZJ316}

As shown in Figure 2, the growth of L. plantarum ZJ316 was affected by adding $50 \mu \mathrm{g} / \mathrm{ml}, 100 \mu \mathrm{g} / \mathrm{ml}, 250 \mu \mathrm{g} / \mathrm{ml}$, $500 \mu \mathrm{g} / \mathrm{ml}$ and $750 \mu \mathrm{g} / \mathrm{ml}$ of mequindox, and the inhibitory effects were found to be dose-dependent. The high concentration of mequindox had strong inhibitory effect on the growth of L. plantarum ZJ316.

\section{Discussion}

Results of this study showed that L. plantarum ZJ316, isolated from infant fecal samples, had a good inhibitory

Table 4 The effects of Lactobacillus on gut villus height $(\mu \mathrm{m})$ and crypt depth $(\mu \mathrm{m})^{\#}$

\begin{tabular}{|c|c|c|c|c|}
\hline & & Group1 & Group2-1 & Group2-2 \\
\hline \multirow[t]{3}{*}{ Ileum } & Villus height (VH) & $479.81 \pm 19.07^{a}$ & $557.92 \pm 19.99^{b}$ & $532.83 \pm 15.34^{b}$ \\
\hline & Crypt depth (CD) & $263.91 \pm 12.56^{\mathrm{a}}$ & $226.01 \pm 13.24^{b}$ & $202.92 \pm 7.46^{\mathrm{b}}$ \\
\hline & $\overline{V H / C D^{*}}$ & $1.89 \pm 0.09^{a}$ & $2.71 \pm 0.17^{b}$ & $2.74 \pm 0.13^{b}$ \\
\hline \multirow[t]{3}{*}{ Jejunum } & Villus height (VH) & $411.18 \pm 14.67^{a}$ & $504.54 \pm 14.06^{b}$ & $534.72 \pm 13.49^{b}$ \\
\hline & Crypt depth (CD) & $280.13 \pm 14.89^{a}$ & $264.14 \pm 15.83^{a}$ & $222.80 \pm 10.54^{b}$ \\
\hline & $\overline{V H / C D}$ & $1.64 \pm 0.14^{\mathrm{a}}$ & $2.07 \pm 0.11^{b}$ & $2.61 \pm 0.17^{c}$ \\
\hline \multirow[t]{3}{*}{$\overline{\text { Duodenum }}$} & Villus height (VH) & $410.10 \pm 11.24^{a}$ & $453.35 \pm 13.17^{b}$ & $576.80 \pm 17.85^{c}$ \\
\hline & Crypt depth (CD) & $221.23 \pm 10.11^{a}$ & $212.45 \pm 10.79^{a}$ & $217.98 \pm 10.60^{\mathrm{a}}$ \\
\hline & $\overline{\mathrm{VH} / \mathrm{CD}}$ & $2.00 \pm 0.13^{a}$ & $2.28 \pm 0.12^{a}$ & $2.88 \pm 0.19^{b}$ \\
\hline
\end{tabular}

\#Group 1 represents samples collected from pigs treated with antibiotics $105 \mathrm{mg} / \mathrm{d}$. Group 2 represents samples collected from pigs treated with L. plantarum ZJ316 $1 \times 10^{9} \mathrm{CFU} /$ d. Group 2-1 represents samples collected immediately after the cessation of $L$. plantarum and Group 2-2 represents samples collected one week after the cessation of $L$. plantarum. All values represent mean \pm standard error.

* Represents the ratio of villus height to crypt depth.

$a, b$ and c Different superscript letters within a row represent statistically significant differences among groups $(p<0.05)$. 
A. Fecal samples (Beginning) A1 A2 A3 A4 A5 A6 A7 A8 A9
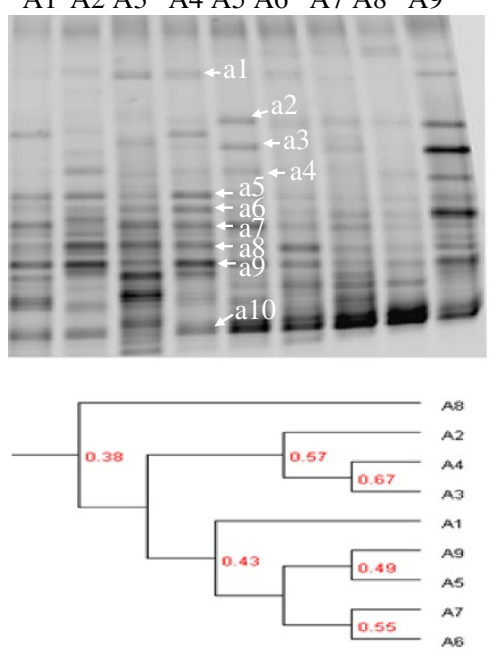

C. Cecal content (End)

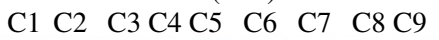

B. Fecal samples (End) B1 B2 B3 B4 B5 B6 B7 B8 B9
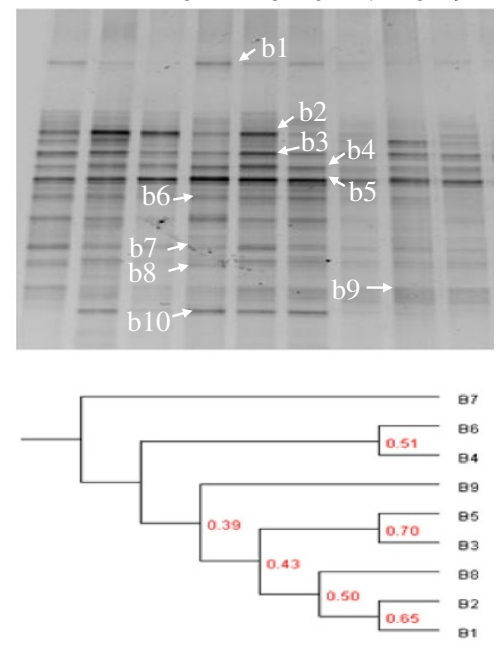

D. Ileum mucosa (End)

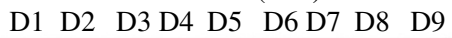

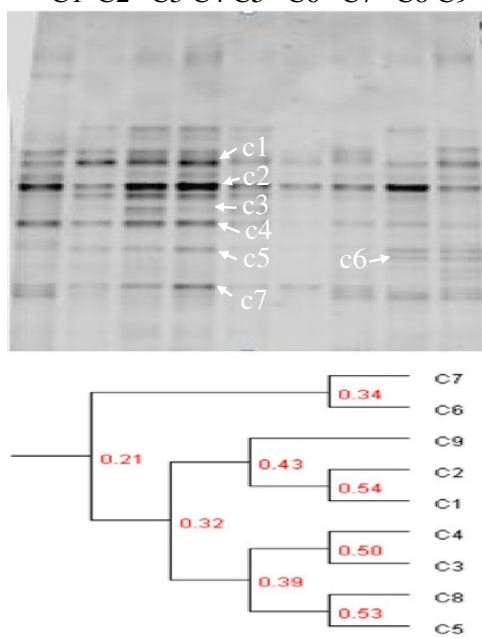

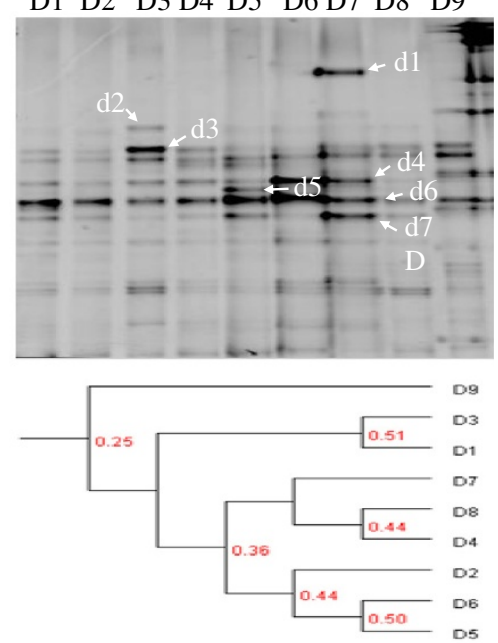

Figure 1 Polymerase chain reaction-denaturing gradient gel electrophoresis (PCR-DGGE) analysis of the gut bacterial community after different treatments. PCR-DGGE of the $16 \mathrm{~S}$ rDNA V3 region was performed to analyze the bacterial community. Similarities were assessed by cluster analysis using Quantity One. (A) Nine fecal samples were randomly collected at the beginning of the experiment. (B, C, and D) Fecal, cecal, and ileal samples collected at the end of the experiment. B1-B3, B4-B6, and B7-B9 represent fecal samples collected from groups 1, 2-1, and 2-2, respectively. C1-C3, C4-C6, and C7-C9 represent cecal contents collected from groups 1, 2-1, and 2-2, respectively. D1-D3, D4-D6, and D7-D9 represent ileal mucosa collected from groups 1, 2-1, and 2-2, respectively. In Group 1, mequindox was added to the subjects' diet. In Group 2-1, L. plantarum ZJ316 was added and mequindox was removed, and samples were collected immediately after halting the addition of $L$. plantarum ZJ316 (day 95). In Group 2-2, L. plantarum ZJ316 was added and mequindox was removed, and samples were collected one week after the cessation of addition of L. plantarum ZJ316 (day 102).

effect on some pathogenic bacteria in vitro. And L. plantarum ZJ316 can significantly improve pig growth at a dose of $1 \times 10^{9} \mathrm{CFU} / \mathrm{d}$ (Group 2). The probiotic effects of L. plantarum ZJ316 are consistent with those observed in previous studies. Foo et al. reported that the effects of feeding Lactobacillus species I-UL4 and their metabolites to weaned rats can improve growth $[13,14]$. Thanh et al. showed that metabolites produced by $L$. plantarum RS5, RI11, RG14 and RG11 strains can improve chicken growth [15].

Although the effects of probiotics usage in pigs are not always consistent, beneficial effects have been documented [16-18]. The mode of action of a given probiotic may include modulation of host microflora [19,20], modifications of the morphology of the intestinal epithelium [21], regulation of the host immunity system [22], and 
Table 5 Identification of PCR-DGGE bands using cloning and sequencing

\begin{tabular}{|c|c|c|c|}
\hline No. & Similar species & No. & Similar species \\
\hline a1 & Erysipelothrix rhusiopathiae & b1 & $\begin{array}{l}\text { Eothenomys smithi HEG193, Streptococcus } \\
\text { hyointestinalis }\end{array}$ \\
\hline a2 & Aerococcus urinaeequi, Weissella paramesenteroides & b2 & $\begin{array}{l}\text { Enterobacteriaceae bacterium, } \\
\text { Streptococcus hyointestinalis, Blautia } \\
\text { glucerasea }\end{array}$ \\
\hline a3 & Anaerococcus tetradius, Clostridium sp. & b3 & $\begin{array}{l}\text { Rumen bacterium NK4B114, Clostridium } \\
\text { cadaveris, Lactobacillus gallinarum }\end{array}$ \\
\hline a4 & Ruminococcus obeum & b4 & $\begin{array}{l}\text { Lachnospira multipara, Bacterium YE62, } \\
\text { Acetivibrio ethanolgignens }\end{array}$ \\
\hline a5 & Eubacterium eligens, Clostridiales bacterium & b5 & Streptococcus gallolyticus subsp. \\
\hline a6 & Rumen bacterium NK4B114 & b6 & Faecalibacterium prausnitzii \\
\hline a7 & Lachnospiraceae bacterium, Blautia glucerasea & b7 & Blautia glucerasea \\
\hline a8 & $\begin{array}{l}\text { Anaerostipes butyraticus, Gemmiger } \\
\text { formicilis, Ruminococcus obeum }\end{array}$ & b8 & Peptoniphilus sp., Faecalibacterium prausnitzii \\
\hline a9 & Eubacterium hadrum, Bacterium YE257 & b9 & Peptococcus sp., Anaerococcus tetradius \\
\hline $\mathrm{a} 10$ & Clostridium cadaveris & b10 & Lactobacillus johnsonii \\
\hline $\mathrm{cl}$ & $\begin{array}{l}\text { Lactobacillus acidophilus, Ruminococcus sp., } \\
\text { Lactobacillus amylolyticus }\end{array}$ & d1 & $\begin{array}{l}\text { Clostridium sordellii, Lachnospira } \\
\text { multipara }\end{array}$ \\
\hline$c 2$ & $\begin{array}{l}\text { Rumen bacterium NK4B114, } \\
\text { Streptococcus gallolyticus subsp. }\end{array}$ & $\mathrm{d} 2$ & Lysinibacillus sp. \\
\hline$c 3$ & Ruminococcus obeum & d3 & $\begin{array}{l}\text { Clostridium nexile, Klebsiella sp., } \\
\text { Clostridiales bacterium }\end{array}$ \\
\hline$c 4$ & Gemmiger formicilis & $\mathrm{d} 4$ & $\begin{array}{l}\text { Eothenomys smithii, Lactobacillus gasseri, } \\
\text { Clostridium cadaveris }\end{array}$ \\
\hline c5 & $\begin{array}{l}\text { Actinomycetales bacterium, Ruminococcus obeum, } \\
\text { Lactobacillus vaginalis }\end{array}$ & d5 & Enterococcus faecium \\
\hline$c 6$ & Blautia glucerasea, Bacterium YE257 & d6 & Streptococcus gallolyticus subsp. \\
\hline c7 & Clostridiales bacterium Clostridium sordellii & d7 & $\begin{array}{l}\text { Peptostreptococcus sp., Staphylococcus sp., } \\
\text { Eubacterium sp. }\end{array}$ \\
\hline
\end{tabular}

the concentration of gut SCFAs, such as acetate [23]. In this study, we investigated the change in gut bacterial community, morphology of ileal mucosa, and the concentration of gut SCFAs due to treatment with L. plantarum ZJ316.

As shown in Figure 1, the bacterial communities in antibiotic- and Lactobacillus-treated groups (Groups 1, 2-1 and 2-2) were very similar. These results showed that the community of gut bacteria was not significantly altered by treatment with L. plantarum ZJ316. Some previous researches have shown similar results. Ohashi et al. showed only a slight change in bacterial communities attributable to orally administered Lactobacillus casei strain Shirota (LCS) [24]. Su et al. also reported no remarkable changes in the overall microbial community in the hind gut after orally administrated L. sobrius S1 [25]. In this study, there are three possible explanations for explain this phenomenon. The first is that the pigs may have developed a stable microbiota after weaning, and this microbiota may be hard to change. Although the porcine GI tract harbors a highly diverse microbial ecosystem [26], Konstantinov et al. reported that once the gut microbiota has matured, it can remain stable for a long time [27]. Second, probiotics, known widely as beneficial bacteria and yeasts, assist in the restoration of normal levels of beneficial microorganisms without destroying the bacterial communities of the GI tract. Third, the ability of this Lactobacillus to colonize the gut epithelium may be low, because the bacterial species used in this experiment was isolated from infant fecal samples. DGGE sequencing results verified this. 34 prominent DGGE bands were extracted for sequencing and the results are listed in Table 5. We can see that, although five bands maybe related to Lactobacillus species, no L. plantarum was found in any of them. Dunne et al. reported that permanent persistence of an allochthonous strain in the host GI microbiota was virtually impossible [28]. L. plantarum is not the predominant Lactobacillus in pigs. L. sobrius was found to be the most dominant species of Lactobacillus in pigs in both pre- and post-weaning $[27,29,30]$. Previous results have also demonstrated that ingested probiotic strains do not become established members of the normal microbiota but persist only for a short time [31-34]. There is also 
Table 6 Concentration of short-chain fatty acids in pig fecal samples ${ }^{\#}$

\begin{tabular}{lccc}
\hline & Group 1 $^{\text {\& }}$ & Group 2 $^{\text {\& }}$ & p-value $^{\S}$ \\
\hline Formic acid & $8.45 \pm 1.13$ & $11.68 \pm 0.39$ & 0.053 \\
\hline Tartaric acid & $0.48 \pm 0.04$ & $0.44 \pm 0.05$ & 0.563 \\
\hline Malic acid & $0.35 \pm 0.07$ & $0.48 \pm 0.09$ & 0.339 \\
\hline Lactic acid & $0.52 \pm 0.07$ & $0.53 \pm 0.01$ & 0.921 \\
\hline Acetic acid & $7.66 \pm 1.80$ & $10.87 \pm 2.71$ & 0.379 \\
\hline Citric acid & $1.76 \pm 0.92$ & $4.33 \pm 2.33$ & 0.363 \\
\hline Propionic acid & $2.47 \pm 0.47$ & $3.04 \pm 0.15$ & 0.317 \\
\hline Butyric acid & $24.92 \pm 1.01$ & $28.57 \pm 4.96$ & 0.511 \\
\hline Isovaleric acid & $1.88 \pm 0.60$ & $3.49 \pm 2.18$ & 0.514 \\
\hline Total & $48.49 \pm 5.38$ & $63.43 \pm 3.79$ & 0.086 \\
\hline
\end{tabular}

\#Group 1 represents samples collected from pigs treated with antibiotic $105 \mathrm{mg} / \mathrm{d}$; Group 2 represents samples collected from pigs treated with $L$. plantarum ZJ316 $1 \times 10^{9} \mathrm{CFU} / \mathrm{d}$. And all values represent mean \pm standard error $\&$, represents the concentration of short-chain fatty acids (mMol) in each gram of fecal sample.

$\S$, represents the p-value of statistically significant difference between groups 1 and 2.

evidence that common probiotic strains differ in their degree of persistence [31,35].

Villi are important components of the digestive tract. They are involved in the absorption of nutrients from the small intestine. The condition of intestinal villi and epithelial cells on the apical surface of the villi is known to be a reliable indicator of the enteral nutrient absorption of feed ingredients in chickens [36] and pigs [37]. However, during post weaning, pigs commonly suffered morphologic atrophy and crypt hyperplasia, which can

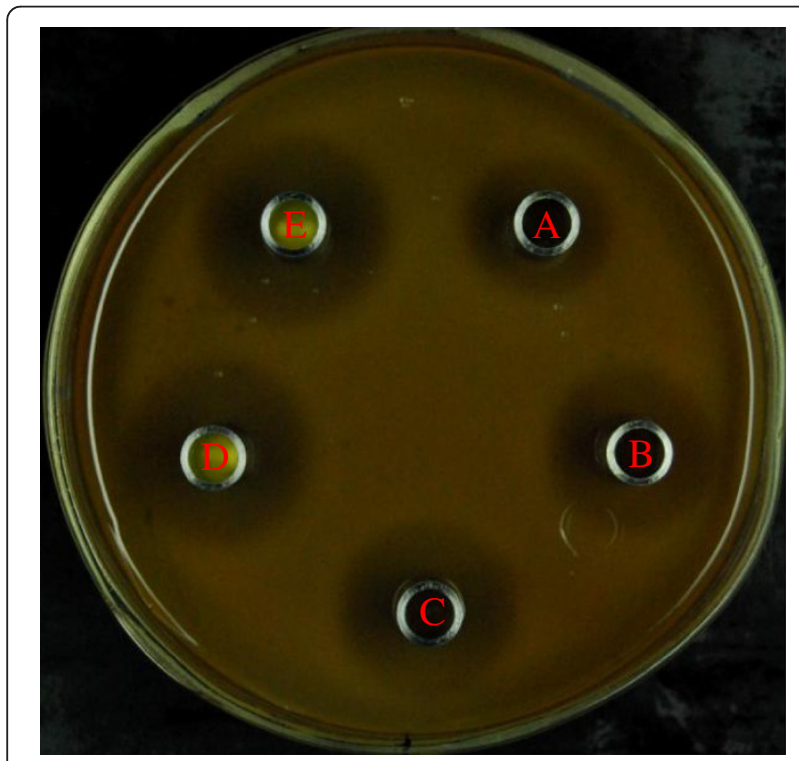

Figure 2 Inhibitory effects of mequindox on $L$. plantarum ZJ316. An Oxford cup test was executed. The inhibitory effects of (A) $50 \mu \mathrm{g} / \mathrm{ml}$, (B) $100 \mu \mathrm{g} / \mathrm{ml}$, (C) $250 \mu \mathrm{g} / \mathrm{ml}$, (D) $500 \mu \mathrm{g} / \mathrm{ml}$ and (E) $750 \mu \mathrm{g} / \mathrm{ml}$ of mequindox were evaluated. limit the absorption of voluntary feed intake and weight gain after weaning $[38,39]$. One characteristic of an effective probiotic is to increase the villus height. SCFAs were considered to be the main factors for stimulating the development of intestinal mucosa [40]. Although the concentration of SCFAs was not significantly different between antibiotic- and Lactobacillus-treated groups (Group 1 and Group 2) in this study (Table 6), the villus height and crypt depth both improved after treatment with L. plantarum ZJ316. There may be other mechanisms by which probiotics can improve intestinal epithelial and villi. It has been established that the effects of probiotic bacteria may also result from soluble factors that can alter epithelial permeability [41]. Two soluble proteins, p40 and p75, were purified from the culture supernatant of Lactobacillus rhamnosus GG (LGG), can prevented TNF-induced apoptosis and intestinal barrier disruption in colonic epithelial cells [42]. The same group also reported that the probiotic LGG can prevent cytokine-induced apoptosis in colon cells through activation the pathways of anti-apoptotic Akt and protein kinase $\mathrm{B}$, and inactivation of the pathway of pro-aptoptic p38 mitogen-activated protein kinase [43].

The effect of L. plantarum ZJ316 on pig growth was found to be dose-dependent. The effects of a dose of $1 \times 10^{9} \mathrm{CFU} / \mathrm{d}$ were more pronounced than those of doses of $5 \times 10^{9} \mathrm{CFU} / \mathrm{d}$ and $1 \times 10^{10} \mathrm{CFU} / \mathrm{d}$. This may be related to cross-talk between the probiotics and the host's immune system. Besides these anti-infective properties, probiotics also act upon the immune and inflammatory response. Probiotic supplementation can enhance SIgA production in both rodents and humans [44]. This appears to be a paradox. Probiotics and nonpathogenic commensals can boost the overall SIgA antibody response, while SIgA can trigger intestinal exclusion and subsequent elimination [45-48]. A high dose of probiotics may induce a strong immune and stress response. Rodrigues et al. reported that germ-free mice colonized with $S$. boulardii displayed more pronounced anti-S. boulardii IgA expression than uncolonized mice [49]. This dose-dependent effect of probiotics has also been observed by other researchers. A change in levels of low-density lipoprotein (LDL) and high-density lipoprotein (HDL) in the blood due can be attributed to the administration of Bifidobacterium animalis subsp lactis (BB-12) and Lactobacillus paracasei subsp paracasei (CRL-431) was dependent on a specific dose of $10^{8}$ for LDL and $10^{9}$ for HDL [50]. A daily dose of Lactobacillus rhamnosus GR-1 plus Lactobacillus fermentum RC-14 at $1.6 \times 10^{9}$ has a better success of restoring and maintaining a normal vaginal flora than doses of $8 \times 10^{8}$ and $6 \times 10^{9}$ [51]. There may be some other mechanisms that may explain this phenomenon. In another study, they found that low bacteria/DC 
(dendritic cells) ratio better regulates the effects on DCs in vitro, suggesting that different intracellular signaling pathways become activated when bacteria are present at high doses [52]. Considering the dose-dependent nature of the effects of $L$. plantarum ZJ316, this may be the reason why mixed treatment group (Group 5, $105 \mathrm{~g}$ mequindox and $1 \times 10^{10} \mathrm{~L}$. plantarum ZJ316 CFU/d) experienced a better probiotic effect than the same dose of antibiotic and probiotic administered alone (Group 1 and Group 4). As shown in Table 2, although the differences between Groups 4 and 5 were not significant, the parameters used for evaluating growth performance had better values for Group 5 than for Groups 1 and 4 . These values were similar to those of the lower dose group (Group 3, $5 \times 10^{9} \mathrm{~L}$. plantarum ZJ316 CFU/d). As shown in Figure 2, mequindox inhibited the growth of $L$. plantarum ZJ316. This shows that mixtures of mequindox and L. plantarum ZJ316 may affect the effective dose of $L$. plantarum ZJ316. This may be why the effects of mixture group more similar to lower dose group (Group 3). Other researches also showed that antibiotics can affect the effects of bacteria-derived probiotics, and should be separated from antibiotics by at least two hours [53].

Here, treatment with L. plantarum also improved pork quality. Significant improvements were observed in Group 2 with regards to hardness, stickiness, chewiness, gumminess, and restoring force. This may meet the nutritional needs of human consumers. Until now, reports on the effects of probioitcs on pork quality have been rare; however, further study is needed.

\section{Conclusion}

The mechanism whereby L. plantarum ZJ316 improved pig growth and pork quality may not be through L. plantarum colonization and alteration of the gut bacterial community. The promotion of pig growth and pork quality may rather be related to the metabolites inhibiting the growth of opportunistic pathogens and increasing the villus height.

\section{Methods}

\section{Animals and experimental design}

One hundred and fifty Landrace-Yorkshire pigs were randomly selected from 26 sows. The ratio of young boars to gilts was about $1: 1$ and the young boars were castrated at 2 weeks. Pigs received no creep feed and were weaned at an age of 28 days. After weaning, pigs were randomly divided into five groups and each group was kept in three pens. In each pen, 10 pigs were selected from 4-5 sows and were kept under standard conditions (natural light regime, humidity of $50-60 \%$, at a temperature of $25 \pm 1{ }^{\circ} \mathrm{C}$ ) at the experimental pig farm of Zhejiang Academy of Agricultural Sciences. Before
Table 7 Composition of the diet used in this study

\begin{tabular}{|c|c|c|c|}
\hline Ingredients & $\mathrm{g} \cdot \mathrm{kg}-1$ & Nutritional level & \\
\hline Corn & 645 & Crude protein, \% & 18.23 \\
\hline Soy bean meal & 250 & Digestible energy (Mcal/kg) & 3.15 \\
\hline Wheat middlings & 50 & Lysine (\%) & 1.13 \\
\hline Fish meal & 20 & Methionine (\%) & 0.36 \\
\hline Limestone & 10.6 & Threonine (\%) & 0.78 \\
\hline Additive $^{a}$ & 10 & Calcium (\%) & 0.76 \\
\hline Calcium Bicarbonate & 5 & Phosphorous (\%) & 0.61 \\
\hline Salt & 3.5 & & \\
\hline L-lysine & 2 & & \\
\hline Choline chloride & 1 & & \\
\hline Fromadriamycin & 0.8 & & \\
\hline LysoforteTM Dry & 0.7 & & \\
\hline Threonine & 0.5 & & \\
\hline Methionine & 0.5 & & \\
\hline Capsozyme & 0.3 & & \\
\hline Phytate & 0.1 & & \\
\hline
\end{tabular}

${ }^{a}$ Additive (amount/kilogram of diet): $\mathrm{Ca}, 849 \mathrm{mg} ; \mathrm{Zn}, 150 \mathrm{mg} ; \mathrm{Fe}, 132 \mathrm{mg} ; \mathrm{Mn}$ $20 \mathrm{mg}$; Cu, $12 \mathrm{mg}$; Se, $0.31 \mathrm{mg}$; 0.79 mg; vitamin A, 1,298 IU; vitamin D3, $260 \mathrm{IU}$; vitamin $\mathrm{E}, 2.4 \mathrm{IU}$; menadione (sodium bisulphate), $0.143 \mathrm{mg}$; vitamin B12, $3.3 \mathrm{mg}$; riboflavin, $0.880 \mathrm{mg}$; d-pantothenic acid, $2.6 \mathrm{mg}$; niacin, $4.4 \mathrm{mg}$.

this study, pigs were raised one week with antibiotic (mequindox) to adjust to the new environment. At weaning, the average pig weight was $7.69 \pm 0.82 \mathrm{~kg}$, and at the beginning of this experiment on day 35 , the average was $11.59 \pm 1.42 \mathrm{~kg}$. During this experiment, all pigs were fed the same basic diet (Table 7) ad libitum. Swine fever vaccine, foot and mouth vaccine, pseudorabies vaccine, and porcine reproductive and respiratory syndrome vaccine were used during this period. In order to determine whether the strain of L. plantarum ZJ316 had any ability to replace the antibiotics, Group 1 was fed a diet containing mequindox; Groups 2, 3 and 4 were fed a diet without antibiotics but with $L$. plantarum ZJ316; and Group 5 was fed a mixture of mequindox and L. plantarum ZJ316. The antibiotic was mixed with feeds and the L. plantarum ZJ316 was administered in drinking water. The concentration of antibiotic used for each pig in groups 1 and 5 was $105 \mathrm{mg} / \mathrm{d}$, and the average concentrations of L. plantarum ZJ316 for each pig in Group 2, 3,4 and 5 were $1 \times 10^{9} \mathrm{CFU} / \mathrm{d}, 5 \times 10^{9} \mathrm{CFU} / \mathrm{d}$, $1 \times 10^{10} \mathrm{CFU} / \mathrm{d}$ and $1 \times 10^{10} \mathrm{CFU} / \mathrm{d}$, respectively. In order to control the concentrations of antibiotics and $L$. plantarum, small portions of food and water containing mequindox or $L$. plantarum were fed to pigs before free feeding. The antibiotic and L. plantarum ZJ316 were given to these pigs every day until the end of this experiment (i.e., $60 \mathrm{~d}$ later). We did not use un-treated pigs as controls because the morbidity and mortality rates are very high among these pigs (more than 20\% in before 
experiments) and the pathogenicity may easily be transferred to other pigs, causing great economic losses.

All pigs used in these experiments were treated according to the current regulation of laboratory animal management in China and approved by the laboratory animal care and usage committee, Zhejiang Academy of Agricultural Sciences.

\section{Isolation and identification of L. Plantarum ZJ316}

Lactobacillus was isolated from an infant fecal samples using Man-Rogosa-Sharpe (MRS) medium (Hopebio, Qingdao, China). In brief, fecal suspension was spread on MRS agar plates and cultured overnight at $37{ }^{\circ} \mathrm{C}$ under anaerobic conditions (MACS1000 Anaerobic Cabinet, Don Whitley, U.K.). Then a single clone was randomly selected and was passed more than 10 times on MRS plates. Morphology observation and Gram staining verified clonal purity. After that, purified bacteria was used for biochemical and molecule identification. The biochemical test results are listed in Additional file 1 Table S1. They showed that these bacteria belong to Lactobacillus. For molecular identification, $16 \mathrm{~S}$ rDNA primer $27 \mathrm{~F}$ (5'-AGA GTT TGA TCC TGG CTC AG-3') and 1492R (5'-GGT TAC CTT GTT ACG ACT T-3') were used in this study. BLAST results showed that this Lactobacillus was more closely related to Lactobacillus plantarum (99\% max identity and 96\% query coverage), and was therefore named Lactobacillus plantarum ZJ316. The $16 \mathrm{~S}$ rDNA sequence has been submitted to NCBI with accession number [GenBank: JN126052].

\section{Antibacterial activity of L. Plantarum ZJ316 culture supernatants}

The inhibitory effects of the raw extraction of L. plantarum ZJ316 culture supernatants were evaluated on 17 bacteria strains (Table 1) using agar plates. An Oxford cup test was selected for this study [54]. In brief, $10 \mathrm{ml}$ of semi-solid medium containing $300 \mu \mathrm{l}$ of indicator bacteria, such as E. coli, was poured onto each agar plate. Then Oxford cups were put on the agar plate. After that, fermented liquid or other activated liquid, such as antibiotic solution, was added to each Oxford cup. After overnight culture, the diameter of the inhibition zone was measured and used as an indicator. In order to reduce possible effects of low $\mathrm{pH}$ of the culture supernatants on E. coli and Salmonella, we adjusted the $\mathrm{pH}$ to 6.0 using $1 \mathrm{~mol} / \mathrm{L} \mathrm{NaOH}$. In addition, the possible inhibitory effects of equivalent acetic acid $(200 \mathrm{mM} / \mathrm{L})$ and lactic acid $(15 \mathrm{mM} / \mathrm{L})$ were assessed using the solutions of these two acids with $\mathrm{pH} 3.5$.

\section{Data and sample collection}

At the end of the study (day 95), average daily feed intakes (ADFI), average daily weight gain (ADG), food conversion ratio (FCR), mortality and diarrheal rate were calculated for evaluating the effects of different treatments on pig growth. The quantity of food provided and food left over was recorded every day, and the ADFI was calculated as follows: (given feed weight - residual feed weight $) /($ number of pigs $\times$ number of days). The ADG was calculated as follows: (average pig weight at the end - average pig weight at the beginning)/(number of days). The FCR was calculated as follows: (ADG/ADFI). The numbers of dead and diarrheal pigs were recorded every day and the ratios were calculated as follows: (number of dead pigs)/(total number of pigs) and (number of diarrheal pigs)/(total number of pigs). Nine pigs were selected for slaughter at the end of the experiment; and then muscle samples were collected for pork quality evaluation, ileal mucosa samples were collected for morphology observation, and ileal mucosa and cecal contents were collected for bacterial community analysis.

\section{Evaluation of pork quality}

After $60 \mathrm{~d}$ of exposure to antibiotics and Lactobacillus, three pigs from Group 1, six pigs from Group 2 (three selected immediately after the cessation of the addition of Lactobacillus, and three selected one week after halting Lactobacillus) were randomly selected for evaluation of pork quality. After slaughter, muscle samples from the Longissimus thoracis (LT, located between the 12th and 13th ribs) and fillet were collected for evaluation of the pork quality. A reflectance spectrophotometer (Minolta CM-2002; Osaka, Japan) was used to measure the color at the surface of a 2-cm-thick steak of Longissimus thoracis muscle after exposure to air for two hours. The parameters registered were $L^{*}$ (lightness), a* (redness), and $\mathrm{b}^{*}$ (yellowness). Each value was the mean of 10 determinations per sample on the same slice, avoiding areas with excess fat.

Muscle $\mathrm{pH}$ was measured at $45 \mathrm{~min}$ and at 24 hours (starting points from the minute the muscles were removed from the corpse) using a portable $\mathrm{pH}$ meter equipped with a glass electrode (Hanna HI 8424, Hanna Instruments, Eibar, Spain). To measure the drip loss, samples were placed on a supporting mesh in a sealed plastic container with no contact between sample and container. Three pigs were selected for sample collection and three muscle samples were collected from each pig. After a storage period of 24 hours and 48 hours at $4{ }^{\circ} \mathrm{C}$, the samples were taken out of the container, dabbed lightly onto filter paper, and weighed again. Drip loss was expressed as a percentage of the initial weight based on Honikel [55]. Marbling scores were calculated according to the NPCC 1999.

Texture profile analysis (TPA) was measured using a TA-XT2 Texture Analyser (Stable Micro Systems, 
Godalming, U.K.) equipped with a $25 \mathrm{~kg}$ load cell. The Texture Expert computer program (version 1.20, Stable Micro Systems) was used for data collection and calculations. Before TPA analysis, samples were vacuumpackaged (DZD-400/2 S, Jiangsu Tengtong Packing Machinery Co., Ltd), placed in a cooler $\left(4{ }^{\circ} \mathrm{C}\right.$, wind velocity of $0.5 \mathrm{~m} / \mathrm{s}$ ) for 7 days, and then frozen on stainless steel trays at $-20{ }^{\circ} \mathrm{C}$. At the beginning of TPA analysis, the samples were fast-thawed in tap water $(4 \mathrm{~h})$. Then the vacuum was broken and the samples were wrapped in aluminum foil and cooked at $200{ }^{\circ} \mathrm{C}$ in a double-plate grill (Sammic GRS-5) until the internal temperature reached $72{ }^{\circ} \mathrm{C}$. After cooking, steaks were placed in a vacuum bag and immediately immersed in an ice bath to stop further cooking. In this study, hardness, stickiness, springiness, chewiness, gumminess, cohesiveness, and restoring force were determined as described by Bourne [56].

\section{Morphologic observation of gut ileal mucosa}

After animals were killed, ileal tissues (approximately $10 \mathrm{~cm}$ anterior to the ileo-cecal junction) were harvested and cut into $1.5 \mathrm{~cm} \times 1.5 \mathrm{~cm} \times 0.3 \mathrm{~cm}$ pieces for sectioning. The pieces were fixed in $10 \%$ formalin after washing with PBS. Then, the formalin-fixed samples were dehydrated in ethanol, cleared with xylene, and embedded in paraffin wax. Sections (6 $\mu \mathrm{m}$ thick) were stained with hematoxylin and eosin and observed using a light microscope (Leica, Germany).

For measurement of villus height and crypt depth, 10 villi and crypts were selected per section using Leica MZ16A software. The villus height was measured from the villus tip to the bottom, not including the intestinal crypt. The crypt depth was measured from the crypt tip to the bottom. An average of 10 villi and crypts per section was expressed as a mean villus height and crypt depth for each pig.

\section{Analysis of the gut bacterial community}

Ileal mucosa (approximately $10 \mathrm{~cm}$ anterior to the ileocecal junction) and cecal contents (5-10 g) were collected after slaughter. Fresh fecal samples were collected at the beginning and end of the experiment, corresponding to 35, 95 and 102 days of age. Some gut samples collected from Group 1, Group 2-1 and Group 2-2 were used for bacterial genomic DNA extraction. In this study, a bead-beating method was used as previously described [57]. The concentration of extracted DNA was determined using a NanoDrop ND-2000 (NanoDrop Technologies, U.S.), and its integrity and size were checked by agar gel electrophoresis (1.0\%). High-quality DNA was then used for polymerase chain reaction $(\mathrm{PCR})$ and denaturing gradient gel electrophoresis (DGGE) analysis. Primer $341 \mathrm{~F}$ (5'-ATT ACC GCG GCT GCT GG-3') and 534R with GC clips (5'-CGC
CCG CCG CGC GCG GCG GGC GGG GCG GGG GCA CGG GGG GCC TAC GGG AGG CAG CAG-3') against the $\mathrm{V} 3$ region of the $16 \mathrm{~S}$ rRNA genes were used in this study. The PCR program included 20 touchdown cycles $\left(65^{\circ} \mathrm{C}-55^{\circ} \mathrm{C}\right.$ ); followed by 5 cycles of $94{ }^{\circ} \mathrm{C}$ for $1 \mathrm{~min}, 55^{\circ} \mathrm{C}$ for $1 \mathrm{~min}$, and $72{ }^{\circ} \mathrm{C}$ for $1 \mathrm{~min}$ followed by extension at $72^{\circ}$ $\mathrm{C}$ for $10 \mathrm{~min}$. Reconditioning PCR was performed before DGGE. DGGE was then performed on a Dcode ${ }^{\mathrm{TM}}$ universal detection system (BIO-RAD Laboratories Inc, U.S.) with $8 \%$ polyacrylamide gels (ratio of acrylamide to bisacrylamide, 37.5:1) at $60{ }^{\circ} \mathrm{C}$. The gels were electrophoresed at $200 \mathrm{~V}$ for $4 \mathrm{~h}$, and then stained with SYBR GREEN I. The bands were visualized and analyzed with Quantity One software (Version 4.6.1; BIO-RAD Laboratories Inc, U.S.) using a match tolerance of $2 \%$.

\section{DGGE band sequencing}

DGGE band sequencing was carried out according to $\mathrm{Li}$ et al. [58]. The stable bands in the DGGE gels verified as single bands were excised and eluted in $30 \mu \mathrm{l}$ TE buffer (10 mM Tris and $1 \mathrm{mM}$ EDTA, pH 8.0). The supernatant after centrifugation $\left(12,000 \mathrm{rpm}, 5 \mathrm{~min}, 4^{\circ} \mathrm{C}\right)$ was used for $16 \mathrm{~S}$ rDNA-V3 amplification with the V3 primers $341 \mathrm{~F}$ and $534 \mathrm{R}$ without GC-clamp using the same program as $\mathrm{Li}$ et al. [58]. The amplification $16 \mathrm{~S}$ rDNA-V3 segments were cloned into a PMD18-T vector after being purified with a Biospin Gel Extraction Kit (Bioer Technology co., Ltd., Japan). The positive recombinants were screened on 5-bromo-4-chloro-3-indolyl-b-D- galactopyranoside (XGal), isopro-pyl-b-D-thiogalactopyranoside (IPTG) and ampicillin indicator plates by color-based recombinant selection. Positive clones were selected for sequencing using an ABI 3730 DNA Sequencer (U.S.) with M13 primer at the Beijing Genomics Institute (BGI, China). In all, 34 DGGE bands were sequenced and most closed sequences were identified using a BLAST search.

\section{Short-chain fatty acids (SCFAs) analysis}

Fecal samples $(0.5 \mathrm{~g})$ were dissolved into $10 \mathrm{ml}$ phosphate buffered saline (PBS), vortexed, and then centrifuged at $12,000 \times \mathrm{g}$ for 10 minutes at $4{ }^{\circ} \mathrm{C}$. Then the supernatants were filtered through a $0.45 \mu \mathrm{m}$ membrane filter for HPLC detection. In this study, the levels of acetic, butyric, citric, formic, isovaleric, lactic, malic, propionic, and tartaric acids were investigated. A Prevail $^{\mathrm{TM}}$ Organic Acid column $(250 \mathrm{~mm} \times 4.6 \mathrm{~mm})$ was used with the detection conditions: temperature, $40{ }^{\circ} \mathrm{C}$; wavelength, $217 \mathrm{~nm}$; pressure, 0.1-4,000 psi.

\section{The inhibitory effects of mequindox on L. Plantarum ZJ316}

An Oxford cup test was executed as described above, and the inhibitory effects of $50 \mu \mathrm{g} / \mathrm{ml}, 100 \mu \mathrm{g} / \mathrm{ml}, 250 \mu \mathrm{g} / \mathrm{ml}$, $500 \mu \mathrm{g} / \mathrm{ml}$ and $750 \mu \mathrm{g} / \mathrm{ml}$ of mequindox were evaluated. 


\section{Statistical analysis}

To analyze growth, each pen from each group was considered a single replicate. For meat color, $\mathrm{pH}$ value, drop loss and marbling score, each pig from each group was considered a single replicate. For meat TPA analysis, three samples were collected from each pig and used as replicates. For gut villus height and crypt depth analysis, 30 values were collected from each group and used as replicates. All of the above data were statistically analyzed using the One-Way ANOVA program included in the statistical software package SPSS 13.0 (IBM, U.S.). Least-significant difference (LSD) was selected for post hoc multiple comparisons. For fatty acid analysis, fecal samples were collected from pigs that had been selected for meat quality evaluation and were considered as replicate. They were then analyzed using the means program included in the statistical software package SPSS 13.0 (IBM, U.S.). All values were presented as mean \pm standard error. $\mathrm{p}<0.05$ was considered significant.

\section{Additional file}

\section{Supplementary Table 1: Fermentation pattern of $L$. plantarum}

ZJ316*. Supplementary Figure 1. Inhibitory effects of the Lactobacillus plantarum ZJ316 culture supernatants at pH 6.0. Culture supernatants of L. plantarum ZJ316 were collected and adjusted to $\mathrm{pH} 6.0$ using $1 \mathrm{~mol} / \mathrm{L}$ $\mathrm{NaOH}$. The inhibitory effects were evaluated on Escherichia coli and Salmonella using agar plates. A: Inhibitory effects of the culture supernatants on Escherichia coli. B: Inhibitory effects of the culture supernatants on Salmonella. Supplementary Figure 2. Comparison of the inhibitory effects of culture supernatants of Lactobacillus plantarum ZJ316 with acetic acid and lactic acid at pH 3.5. Salmonella was used as indicator bacteria for comparing the inhibitory effects at pH 3.5. 1, represents culture supernatants of Lactobacillus plantarum ZJ316 was added into the Oxford; 2 , represents lactic acid was added into the Oxford and 3, represents acetic acid was added into the Oxford.

\section{Authors' contributions}

CS performed the pig growth experiment and carried out the data analyses; YY designed the experiments, carried out data analyses, and drafted the manuscript; XW performed the pork quality experiment; XL performed the inhibitory experiment of antibiotic; DS isolated the Lactobacillus strain and assisted with the pork quality experiment; XW designed the experiments and revised the manuscript; QG designed the experiments, carried out data analyses, and drafted the manuscript. All authors read and approved the final manuscript.

\section{Acknowledgements}

This research was kindly supported by the National Natural Science Foundation of China (No. 31071513, No. 30970108, No. 31100097), the Natural Science Foundation of Zhejiang Province (No. Z3110399), and the Program for Science and Technology from Zhejiang Province (No. 2007 C12037). We would also like to thank Mr. Thomas Ryan Withers of Marshall University for editing this paper. We would especially like to thank the anonymous reviewers for their constructive suggestions and critiques.

\section{Author details}

'Department of Biotechnology, College of Food Science and Biotechnology, Zhejiang Gongshang University, No. 149, Jiaogong Road, Hangzhou 310035, China. ${ }^{2}$ Institute of Plant Protection and Microbiology, Zhejiang Academy of Agricultural Sciences, No. 198, Shiqiao Road, Hangzhou 310021, China.

Received: 30 December 2011 Accepted: 14 June 2012 Published: 25 June 2012

\section{References}

1. Su Y, Yao W, Perez-Gutierrez ON, Smidt H, Zhu WY: Changes in abundance of Lactobacillus spp. and Streptococcus suis in the stomach, jejunum and ileum of piglets after weaning. FEMS Microbiol Ecol 2008, 66(3):546-555.

2. Jones FT, Langlois BE, Cromwell GL, Hays WW: Effect of chlortetracycline on the spread of R-100 plasmid-containing Escherichia coli BEL15R from experimentally infected pigs to uninfected pigs and chicks. J Anim Sci 1984, 58(3):519-526.

3. Gay PB, Gillespie SH: Antibiotic resistance markers in genetically modified plants: a risk to human health? Lancet Infect Dis 2005, 5(10):637-646.

4. Ahmed AM, Motoi Y, Sato M, Maruyama A, Watanabe H, Fukumoto Y, Shimamoto T: Zoo animals as reservoirs of gram-negative bacteria harboring integrons and antimicrobial resistance genes. Appllied Environ Microbiol 2007, 73(20):6686-6690.

5. Ewing W, Cole D: The Living Gut. An Introduction to Micro-organisms in Nutrition. Ireland, UK: Context Publication; 1994:45-65.

6. Jensen BB: Possible ways of modifying type and amount of products from microbial fermentation in the gut. In in Gut Environment of Pigs. Edited by Piva A, Bach Knudsen KE, Lindberg JE. UK: Nottingham University Press; 2001.

7. Zhang L, Xu YQ, Liu HY, Lai T, Ma JL, Wang JF, Zhu YH: Evaluation of Lactobacillus rhamnosus GG using an Escherichia coli K88 model of piglet diarrhoea: Effects on diarrhoea incidence, faecal microflora and immune responses. Vet Microbiol 2010, 141(1-2):142-148.

8. Blomberg L, Henriksson A, Conway PL: Inhibition of adhesion of Escherichia coli K88 to piglet ileal mucus by Lactobacillus spp. App/ Environ Microbiol 1993, 59(1):34-39.

9. Wang C, Wang J, Gong J, Yu H, Pacan JC, Niu Z, Si W, Sabour PM: Use of Caenorhabditis elegans for Preselecting Lactobacillus Isolates To Control Salmonella Typhimurium. J Food Prot 2011, 74(1):86-93.

10. de Vries MC, Vaughan EE, Kleerebezem M, de Vos WM: Lactobacillus plantarum-survival, functional and potential probiotic properties in the human intestinal tract. Int Dairy J 2008, 16:1018-1028.

11. Pieper R, Janczyk P, Urubschurov V, Korn U, Pieper B, Souffrant WB: Effect of a single oral administration of Lactobacillus plantarum DSMZ 8862/8866 before and at the time point of weaning on intestinal microbial communities in piglets. Int J Food Microbiol 2009, 130(3):227-232.

12. Lallès JPPB, Hauke S, Chris RS: Weaning-A challenge to gut physiologists. Livest Sci 2007, 108:82-93.

13. Foo HL, Loh TC, Law FL, Lim YS, Kufli CN, Rusul G: Effect of feeding L. plantarum I-UL4 isolated from Malaysian Tempeh on growth performance, faecal flora and lactic acid bacteria and plasma cholesterol concentrations in post-weaning rats. Food Sci Biotechnol 2003, 12:403-408.

14. Foo HL, Loh TC, Lai PW, Lim YZ, Kufli CN, Rusul G: Effects of adding L. plantarum I-UL4 metabolites in drinking water of rats. Pak J Nutr 2003, 2:283-288.

15. Thanh NT, Loh TC, Foo HL, Hair-Bejo M, Azhar BK: Effects of feeding metabolite combinations produced by Lactobacillus plantarum on growth performance, faecal microbial population, small intestine villus height and faecal volatile fatty acids in broilers. Br Poult Sci 2009, 50(3):298-306.

16. Alexopoulos C, Georgoulakis IE, Tzivara A, Kyriakis CS, Govaris A, Kyriakis SC: Field evaluation of the effect of a probiotic-containing Bacillus licheniformis and Bacillus subtilis spores on the health status, performance, and carcass quality of grower and finisher pigs. J Vet Med A Physiol Pathol Clin Med 2004, 51(6):306-312.

17. Duncker SC, Lorentz A, Schroeder B, Breves G, Bischoff SC: Effect of orally administered probiotic E. coli strain Nissle 1917 on intestinal mucosal immune cells of healthy young pigs. Vet Immunol Immunopathol 2006, 111(3-4):239-250.

18. Davis ME, Parrott $T$, Brown DC, de Rodas BZ, Johnson ZB, Maxwell CV, Rehberger T: Effect of a Bacillus-based direct-fed microbial feed supplement on growth performance and pen cleaning characteristics of growing-finishing pigs. J Anim Sci 2008, 86(6):1459-1467.

19. Rastall RA, Gibson GR, Gill HS, Guarner F, Klaenhammer TR, Pot B, Reid G, Rowland IR, Sanders ME: Modulation of the microbial ecology of the human colon by probiotics, prebiotics and synbiotics to enhance human health: an overview of enabling science and potential applications. FEMS Microbiol Ecol 2005, 52(2):145-152.

20. Fooks $\sqcup$, Gibson GR: Probiotics as modulators of the gut flora. Br J Nutr 2002, 88(Suppl 1):S39-S49. 
21. Boirivant M, Strober W: The mechanism of action of probiotics. Curr Opin Gastroenterol 2007, 23(6):679-692

22. Corthesy B, Gaskins HR, Mercenier A: Cross-talk between probiotic bacteria and the host immune system. J Nutr 2007, 137(3 Suppl 2):781S-790S.

23. Fukuda S, Toh H, Hase K, Oshima K, Nakanishi Y, Yoshimura K, Tobe T, Clarke JM, Topping DL, Suzuki T, Taylor TD, Itoh K, Kikuchi J, Morita H, Hattori M, Ohno $\mathrm{H}$ : Bifidobacteria can protect from enteropathogenic infection through production of acetate. Nature 2011, 469(7331):543-547.

24. Ohashi $Y$, Tokunaga M, Ushida K: The effect of Lactobacillus casei strain Shirota on the cecal fermentation pattern depends on the individual cecal microflora in pigs. J Nutr Sci Vitaminol (Tokyo) 2004, 50(6):399-403.

25. Su Y, Yao W, Perez-Gutierrez ON, Smidt H, Zhu WY: 16 S ribosomal RNAbased methods to monitor changes in the hindgut bacterial community of piglets after oral administration of Lactobacillus sobrius S1. Anaerobe 2008, 14(2):78-86.

26. Leser TD, Amenuvor JZ, Jensen TK, Lindecrona RH, Boye M, Moller K: Culture-independent analysis of gut bacteria: the pig gastrointestinal tract microbiota revisited. Appl Environ Microbiol 2002, 68(2):673-690.

27. Konstantinov SR, Poznanski E, Fuentes S, Akkermans AD, Smidt H, de Vos WM: Lactobacillus sobrius sp. nov., abundant in the intestine of weaning piglets. Int J Syst Evol Microbiol 2006, 56(Pt 1):29-32.

28. Dunne C, Murphy L, Flynn S, O'Mahony L, O'Halloran S, Feeney M, Morrissey D, Thornton G, Fitzgerald G, Daly C, et al: Probiotics: from myth to reality. Demonstration of functionality in animal models of disease and in human clinical trials. Antonie Van Leeuwenhoek 1999, 76(1-4):279-292.

29. Konstantinov SR, Awati A, Smidt H, Williams BA, Akkermans AD, de Vos WM: Specific response of a novel and abundant Lactobacillus amylovorus-like phylotype to dietary prebiotics in the guts of weaning piglets. Appl Environ Microbiol 2004, 70(7):3821-3830.

30. Konstantinov SR, Awati AA, Williams BA, Miller BG, Jones P, Stokes CR, Akkermans AD, Smidt $H$, de Vos WM: Post-natal development of the porcine microbiota composition and activities. Environ Microbiol 2006, 8(7):1191-1199.

31. Fuller R: Probiotics in human medicine. Gut 1991, 32(4):439-442.

32. Tannock GW: Probiotic properties of lactic-acid bacteria: plenty of scope for fundamental R \& D. Trends Biotechnol 1997, 15(7):270-274.

33. Gardiner GE, Casey PG, Casey G, Lynch PB, Lawlor PG, Hill C, Fitzgerald GF, Stanton C, Ross RP: Relative ability of orally administered Lactobacillus murinus to predominate and persist in the porcine gastrointestinal tract. Appl Environ Microbiol 2004, 70(4):1895-1906.

34. Klingberg TD, Budde BB: The survival and persistence in the human gastrointestinal tract of five potential probiotic lactobacilli consumed as freeze-dried cultures or as probiotic sausage. Int J Food Microbiol 2006, 109(1-2):157-159.

35. Rastall RA: Bacteria in the gut: friends and foes and how to alter the balance. J Nutr 2004, 134(8 Suppl):2022S-2026S.

36. Maneewan B, Yamauchi K: Recovery of duodenal villi and cells in chickens refed protein, carbohydrate and fat. Br Poult Sci 2005, 46(4):415-423.

37. Mekbungwan A, Yamauchi K: Growth performance and histological intestinal alterations in piglets fed dietary raw and heated pigeon pea seed meal. Histol Histopathol 2004, 19(2):381-389.

38. Loh TC, Choo PY, Cheong YH: Effects of organic acid and natural herbs on performance and incidence of diarrhoea in postweaning pigs. Malaysian J Animal Sci 2002, 7(2):25-30.

39. Hedemann MS, Hojsgaard S, Jensen BB: Small intestinal morphology and activity of intestinal peptidases in piglets around weaning. J Anim Physiol Anim Nutr (Berl) 2003, 87(1-2):32-41.

40. von Engelhardt W, Bartels J, Kirschberger S, Duttingdorf HD Meyer zu, Busche R: Role of short-chain fatty acids in the hind gut. Vet Q 1998, 20(Suppl 3):S52-S59.

41. Madsen K, Cornish A, Soper P, McKaigney C, Jijon H, Yachimec C, Doyle J, Jewell $L$, De Simone C: Probiotic bacteria enhance murine and human intestinal epithelial barrier function. Gastroenterology 2001, 121(3):580-591.

42. Yan F, Cao H, Cover TL, Whitehead R, Washington MK, Polk DB: Soluble proteins produced by probiotic bacteria regulate intestinal epithelial cell survival and growth. Gastroenterology 2007, 132(2):562-575.

43. Yan F, Polk DB: Probiotic bacterium prevents cytokine-induced apoptosis in intestinal epithelial cells. J Biol Chem 2002, 277(52):50959-50965.

44. Saulnier N, Zocco MA, Di Caro S, Gasbarrini G, Gasbarrini A: Probiotics and small bowel mucosa: Molecular aspects of their interactions. Genes Nutr 2006, 1(2):107-115
45. Tejada-Simon MV, Lee JH, Ustunol Z, Pestka JJ: Ingestion of yogurt containing Lactobacillus acidophilus and Bifidobacterium to potentiate immunoglobulin A responses to cholera toxin in mice. J Dairy Sci 1999, 82(4):649-660.

46. Fukushima Y, Kawata Y, Hara H, Terada A, Mitsuoka T: Effect of a probiotic formula on intestinal immunoglobulin A production in healthy children. Int J Food Microbiol 1998, 42(1-2):39-44.

47. Fang $H$, Elina $T$, Heikki A, Seppo S: Modulation of humoral immune response through probiotic intake. FEMS Immunol Med Microbiol 2000, 29(1):47-52.

48. Cukrowska B, Lodlnova-Zadnlkova R, Enders C, Sonnenborn U, Schulze J, Tlaskalova-Hogenova $\mathrm{H}$ : Specific proliferative and antibody responses of premature infants to intestinal colonization with nonpathogenic probiotic E. coli strain Nissle 1917. Scand J Immunol 2002, 55(2):204-209.

49. Rodrigues AC, Cara DC, Fretez SH, Cunha FQ, Vieira EC, Nicoli JR, Vieira LQ: Saccharomyces boulardii stimulates slgA production and the phagocytic system of gnotobiotic mice. J Appl Microbiol 2000, 89(3):404-414

50. Larsen CN, Nielsen S, Kaestel P, Brockmann E, Bennedsen M, Christensen HR, Eskesen DC, Jacobsen BL, Michaelsen KF: Dose-response study of probiotic bacteria Bifidobacterium animalis subsp lactis BB-12 and Lactobacillus paracasei subsp paracasei CRL-341 in healthy young adults. Eur J Clin Nutr 2006, 60(11):1284-1293.

51. Reid G, Beuerman D, Heinemann C, Bruce AW: Probiotic Lactobacillus dose required to restore and maintain a normal vaginal flora. FEMS Immunol Med Microbio/ 2001, 32(1):37-41.

52. Smits $H H$, Engering $A$, van der Kleij $D$, de Jong EC, Schipper $K$, van Capel TM, Zaat BA, Yazdanbakhsh M, Wierenga EA, van Kooyk Y, et al: Selective probiotic bacteria induce IL-10-producing regulatory $T$ cells in vitro by modulating dendritic cell function through dendritic cell-specific intercellular adhesion molecule 3-grabbing nonintegrin. J Allergy Clin Immunol 2005, 115(6):1260-1267.

53. Williams NT: Probiotics. Am J Health Syst Pharm 2010, 67(6):449-458.

54. State-Pharmacopoeia-Committee-of-China: The Pharmacopoeia of People's Republic of China. Beijing: Chemical Industry Press; 2000. second ed.

55. Honikel KO: Quality of ecologically produced foods of animal origin. Dtsch Tierarztl Wochenschr 1998, 105(8):327-329.

56. Bourne MC: Texture profile analysis. Food Technology 1978, 33:62-66.

57. Leser TD, Lindecrona RH, Jensen TK, Jensen BB, Moller K: Changes in bacterial community structure in the colon of pigs fed different experimental diets and after infection with Brachyspira hyodysenteriae. Appl Environ Microbiol 2000, 66(8):3290-3296.

58. Li Z, He L, Wu J, Jiang Q: Bacterial community diversity associated with four marine sponges from the South China Sea based on $16 \mathrm{~S}$ rDNADGGE fingerprinting. J Exp Marine Biol Ecol 2006, 329:75-85.

doi:10.1186/1746-6148-8-89

Cite this article as: Suo et al:: Effects of lactobacillus plantarum ZJ316 on pig growth and pork quality. BMC Veterinary Research 2012 8:89.

\section{Submit your next manuscript to BioMed Central and take full advantage of:}

- Convenient online submission

- Thorough peer review

- No space constraints or color figure charges

- Immediate publication on acceptance

- Inclusion in PubMed, CAS, Scopus and Google Scholar

- Research which is freely available for redistribution 